\title{
Editorial: New Directions
}

The Human Agent, the first volume of the Royal Institute of Philosophy Lecture Series, containing lectures delivered during the session I966-67, was published in 1968. The first of the Royal Institute of Philosophy's biennial conferences was held in $197 \mathrm{I}$, and resulted in the publication in I974 of Philosophy of Psychology edited by S. C. Brown. The first series of Benefactors' Lectures was given by Professor Roderick M. Chisholm during the summer of 1979 . It is not an accident that all these dates belong to the term of office of Professor Godfrey Vesey as Director of the Institute. By his own ingenuity and energy, and by being the cause of liveliness in others, he has extended the activities of the Institute in valuable new directions, while continuing to lead it with judgment and discretion in the fulfilment of its traditional purposes. The same qualities have been shown in his work as Professor of Philosophy at the Open University since 1969, and in his own philosophical publications.

Professor Vesey has decided to retire from the directorship in October I979 after holding the office for fourteen years. He first joined the staff as Assistant Editor of Philosophy in 1964 and he acted as Director after the death of $\mathrm{Mr}$ Robertson in 1964 . In recognition of his long and distinguished service, the Council has elected Professor Vesey to be a Fellow of the Royal Institute of Philosophy. He and Mrs Vesey take with them the gratitude, congratulations and good wishes of their colleagues at Gordon Square, of the Council and the Executive Committee, and of all the members of the Institute.

The Council has appointed Professor A. Phillips Griffiths, Professor of Philosophy at the University of Warwick, to the office of Director from October 1979. Professor Phillips Griffiths is well known for his published work, including his contributions to a number of Royal Institute publications. Many students and teachers of philosophy have reason to be grateful for his Knowledge and Belief in the Oxford paperback series Readings in Philosophy. He is well equipped by natural gifts and experience to take up the absorbing and exacting duties of his new office.

This report on some changes needs to be supplemented by a report on some continuities. The Council are happy to announce that Dr Stuart Brown has accepted reappointment to the office of Assistant Director which he has held since 1969 . He will continue to bear the main responsibility for the organization of the Institute's conferences. And Mrs Joan Joyce, who celebrates this year the twenty-fifth anniversary of her appointment to the staff of the Institute, will continue her invaluable service as Secretary. 